\title{
sciendo
}

\author{
BULGARIAN ACADEMY OF SCIENCES
}

CYBERNETICS AND INFORMATION TECHNOLOGIES • Volume 20, No 2

Sofia $\bullet 2020 \quad$ Print ISSN: 1311-9702; Online ISSN: 1314-4081

DOI: $10.2478 /$ cait-2020-0013

\section{Developing the Expert Decision-Making Algorithm Using the Methods of Multi-Criteria Analysis}

\section{Irakli Basheleishvili}

Akaki Tsereteli State University, Department of Computer Technology, Kutaisi 4600, Georgia E-mails: basheleishvili.irakli@gmail.com Irakli.basheleishvili@atsu.edu.ge

Abstract: The paper deals with the development of an expert decision-making algorithm using the AHP and TOPSIS methods of multi-criteria analysis. In the proposed algorithm, the AHP and TOPSIS methods are used in combination; in particular the AHP method is used to determine the vector of the alternatives' weights, while the TOPSIS method is used assessing and ranking the alternatives. The obtained algorithm ensures optimal decision making based on the experts' assessments. A simple web application has been developed to demonstrate the algorithm's performance.

Keywords: Decision-making, multi-criteria analysis, expert, decision matrix, AHP, TOPSIS.

\section{Introduction}

In any company or organization, there is an ongoing decision-making process, on whose outcome the future of the company depends directly, consequently, the decision-making process is of the greatest challenges. This type of challenge is analytical and requires the optimal assessment for a given particular situation.

To meet such challenges, of high relevance is the use the information systems, which are called the decision support systems [1]. This is a special-type information system based on a model or knowledge, which is intended for supporting managerial decision-making activities. As is known, an important component of a decision support system is a mathematical model, through which, the decision can be analysed and the optimal decision can be made [2-4].

At present, there are decision-making problems, in which all possible alternatives are assessed based on several criteria, and such problems are the decision-making multi-criteria problems [2-5]. There are numerous theoretical approaches to such challenges, but they are hardly used and are time-consuming. Accordingly, of high relevance is to develop effective algorithm for the multi-criteria decision. 
The aim of this study is to develop an algorithm for expert decision making using the AHP and TOPSIS methods [5-8], in which, the use of AHP method allows for determining the criterion weight, which is an important parameter in the decisionmaking problem, while the use of TOPSIS method allows for ranking the alternatives.

\section{Problem statement}

The challenge concerns the problems of multi-expert decision making in a multicriteria environment when making multi-alternative choices in an uncertain environment. The experts, whose assessments are the basis for making particular decision, play in important role in the expert decision-making problem.

The problem of expert decision can be formulated as follows: the set of the alternatives $A=\left\{A_{1}, A_{2}, \ldots, A_{n}\right\}$ is known and the set of the alternatives assessment criteria $C=\left\{C_{1}, C_{2}, \ldots, C_{m}\right\}$ also; we should determine the set of the weights $W=\left\{w_{1}, w_{2}, \ldots, w_{m}\right\} . E=\left\{E_{1}, E_{2}, \ldots, E_{t}\right\}$ is a set of experts, who are an essential part of problem, since, as mentioned above, they are major sources of information in the decision-making problem, because they define the alternative assessments according to the criteria.

To solve the set problem, the developed algorithm consists of the following eight steps

Step 1. Let us determine the decision-making hierarchical structure, alternatives and criteria.

Step 2. Let us draw up a matrix of decision, whose rows represent the alternatives, while columns represent the alternatives assessment criteria:

$$
D=\begin{array}{l|lllll} 
& C_{1} & C_{2} & C_{3} & \cdots & C_{m} \\
\hline A_{1} & x_{11} & x_{12} & x_{13} & \cdots & x_{1 m} \\
A_{2} & x_{21} & x_{22} & x_{23} & \cdots & x_{2 m} \\
A_{3} & x_{31} & x_{32} & x_{33} & \cdots & x_{3 m} \\
\vdots & \vdots & \vdots & \vdots & \ddots & \vdots \\
A_{n} & x_{n 1} & x_{n 2} & x_{n 3} & \cdots & x_{n m}
\end{array},
$$

where $x_{i j}, i=1, \ldots, n$, and $j=1, \ldots, m$, represents the assessment of the $i$ alternative in accordance with $j$ criterion, which are defined by the experts. The value of $x_{i j}$ is calculated as follows:

$$
x_{i j}=\frac{1}{t}\left(x_{i j}^{1}+x_{i j}^{2}+x_{i j}^{3}+\ldots+x_{i j}^{t}\right),
$$

$x_{i j}^{k}, k=1, \ldots, t$, is $k$-th expert assessment of $j$ criterion of the $i$ alternative.

Step 3. Let us determine the alternatives assessment criteria weights, for which we should proceed as it is follow. 
Let us draw up a matrix $(m \times m)$ of comparing criteria in pairs $\left(\left\{C_{1}, C_{2}, \ldots, C_{m}\right\}\right)$, whose rows and columns represent criteria, the values of elements of which are determined according to scale shown in Table 1. Pair-wise comparison matrix is created with the help of scale of relative importance (Table 1):

$$
W=\begin{array}{l|lllll} 
& C_{1} & C_{2} & C_{3} & \cdots & C_{m} \\
\hline C_{1} & z_{11} & z_{12} & z_{13} & \cdots & z_{1 m} \\
C_{2} & z_{21} & z_{22} & z_{23} & \cdots & z_{2 m} \\
C_{3} & z_{31} & z_{32} & z_{33} & \cdots & z_{3 m} \\
\vdots & \vdots & \vdots & \vdots & \ddots & \vdots \\
C_{m} & z_{m 1} & z_{m 2} & z_{m 3} & \cdots & z_{m m}
\end{array},
$$

where

$$
\begin{gathered}
z_{i i}=1, i=1, \ldots, m, \\
z_{j i}=1 / z_{i j}, i \neq j, i, j=1, \ldots, m .
\end{gathered}
$$

Table 1. Scale of relative importance

\begin{tabular}{|c|c|}
\hline Intensity & Definition \\
\hline 1 & Equal importance \\
\hline 3 & Moderate importance \\
\hline 5 & Strong importance \\
\hline 7 & Demonstrated importance \\
\hline 9 & Extreme importance \\
\hline $2,4,6,8$ & $\begin{array}{c}\text { Mean values between two adjacent } \\
\text { assessments }\end{array}$ \\
\hline
\end{tabular}

Calculate the normalized pair-wise comparison matrix:

(4)

$$
\mathrm{AN}_{i j}=\frac{z_{i j}}{\sum_{i=1}^{m} z_{i j}} .
$$

Determine a vector of the weights $W=\left\{w_{1}, w_{2}, \ldots, w_{m}\right\}$ for assessment criteria, which should meet the following conditions:

$$
w_{i}=\sum_{j=1}^{m} \mathrm{AN}_{i j} / m \text {. }
$$

Calculate the weighted normalized decision matrix:

Calculate the sum of weighted values:

$$
\mathrm{AW}_{i j}=w_{j} \times z_{i j} \text {. }
$$

$$
\mathrm{WSV}_{i}=\sum_{j=1}^{m} \mathrm{AW}_{i j}
$$

Calculate $\lambda_{\max }$ :

$$
\lambda_{\max }=\frac{1}{m}\left(\sum_{i=1}^{m} \mathrm{WSV}_{i} / w_{i}\right)
$$


Calculate Consistency Index (CI):

(9)

$$
\mathrm{CI}=\frac{\lambda_{\max }-m}{m-1} \text {. }
$$

Consistency Ratio (CR) is defined as

$$
\mathrm{CR}=\frac{\mathrm{CI}}{\mathrm{RCI}},
$$

where RCI is a random consistency index defined in Table 2.

Table 2. Random consistency index
\begin{tabular}{|c|c|c|c|c|c|c|c|c|c|c|}
\hline$m$ & 1 & 2 & 3 & 4 & 5 & 6 & 7 & 8 & 9 & 10 \\
\hline RI & 0 & 0 & 0.58 & 0.9 & 1.12 & 1.24 & 1.32 & 1.41 & 1.45 & 1.49 \\
\hline
\end{tabular}

Step 4. Calculate the normalized decision matrix:

$$
r_{i j}=\frac{x_{i j}}{\sqrt{\sum_{i=1}^{n} x_{i j}^{2}}} .
$$

Step 5. Calculate the weighted normalized decision matrix:

Step 6. Determine the positive ideal and negative ideal solutions: positive ideal solution is

$$
S^{+}=\left\{v_{1}^{+}, v_{2}^{+}, \ldots, v_{n}^{+}\right\},
$$

where

$$
v_{j}^{+}=\max \left(v_{i j}\right), i=1, \ldots, n, j=1, \ldots, m ;
$$

negative ideal solution is

$$
S^{-}=\left\{v_{1}^{-}, v_{2}^{-}, \ldots, v_{n}^{-}\right\},
$$

where

$$
v_{j}^{-}=\min \left(v_{i j}\right), i=1, \ldots, n, j=1, \ldots, m .
$$

Step 7. Calculate the separation measures from the positive ideal solution and the negative ideal solution. The separations from the ideal alternative are:

$$
\begin{aligned}
& d_{i}^{+}=\sqrt{\sum_{j=1}^{m}\left(v_{i j}-v_{j}^{+}\right)^{2}}, \\
& d_{i}^{-}=\sqrt{\sum_{j=1}^{m}\left(v_{i j}-v_{j}^{-}\right)^{2}},
\end{aligned}
$$

where $i=1,2, \ldots, n$.

Step 8. Calculate the relative closeness to the positive ideal solution. This is calculated by the following formula:

$$
\begin{gathered}
R_{i}=\frac{d_{i}^{-}}{d_{i}^{-}+d_{i}^{+}}, \\
0 \leq R_{i} \leq 1 .
\end{gathered}
$$




\section{Software}

Based on the algorithm presented in this paper, simple software was developed as a web application that provides a solution to the decision-making problem.

The application software was developed in the programming language PHP the database was developed in a database management system MySQL. There are two types of user experts and the administrator in this application.

The administrator identifies the decision-making problem in a system, the alternatives and the assessment criteria for these alternatives in accordance with the decision-making problem, manages the experts accounting records, draws up a decision matrix based on the experts' assessments in accordance with the decisionmaking problem, and assesses and ranks the alternatives by means of the developed algorithm.

The experts in the proposed system have their own space and they make their assessments according to the alternatives and criteria relevant to the decision-making problem.

The user interface fragments of the developed software are provided below.

Fig. 1 presented the form of the decision-making problem definition.

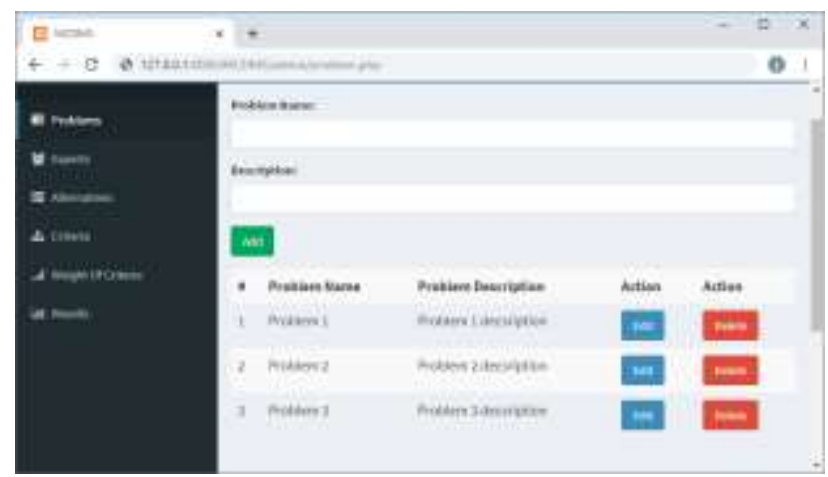

Fig. 1. Form of identifying the decision-making problem

Fig. 2 presents the form of determining alternatives according to the decision-making problem.

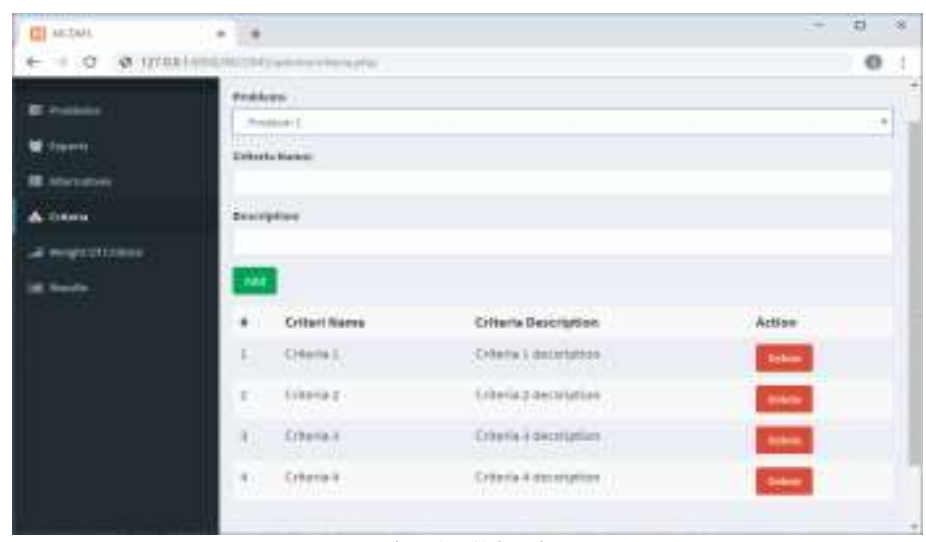

Fig. 2. Criteria 
Fig. 3 presents the form of determining criteries weight.

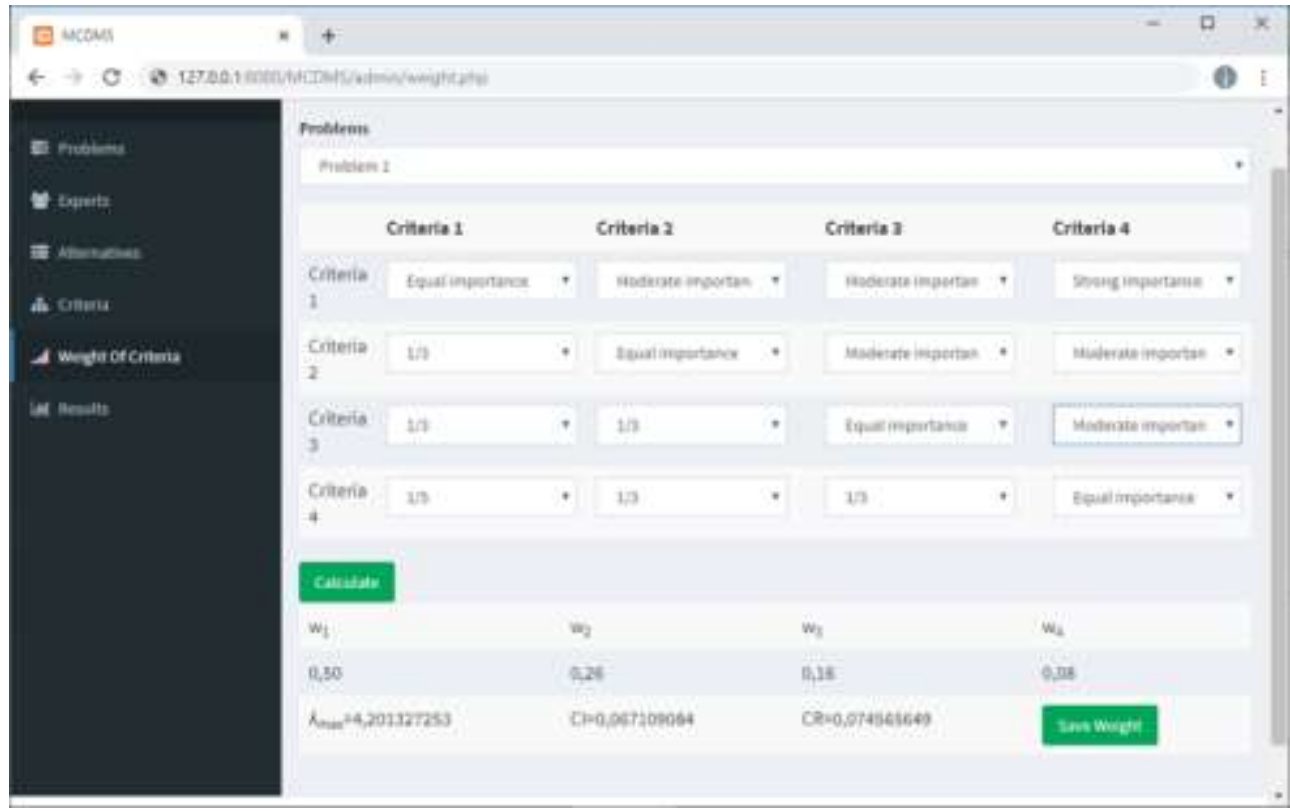

Fig. 3. Wight of criteria

Fig. 4 presents the form of evaluation of alternatives and criteria.

Alternative:

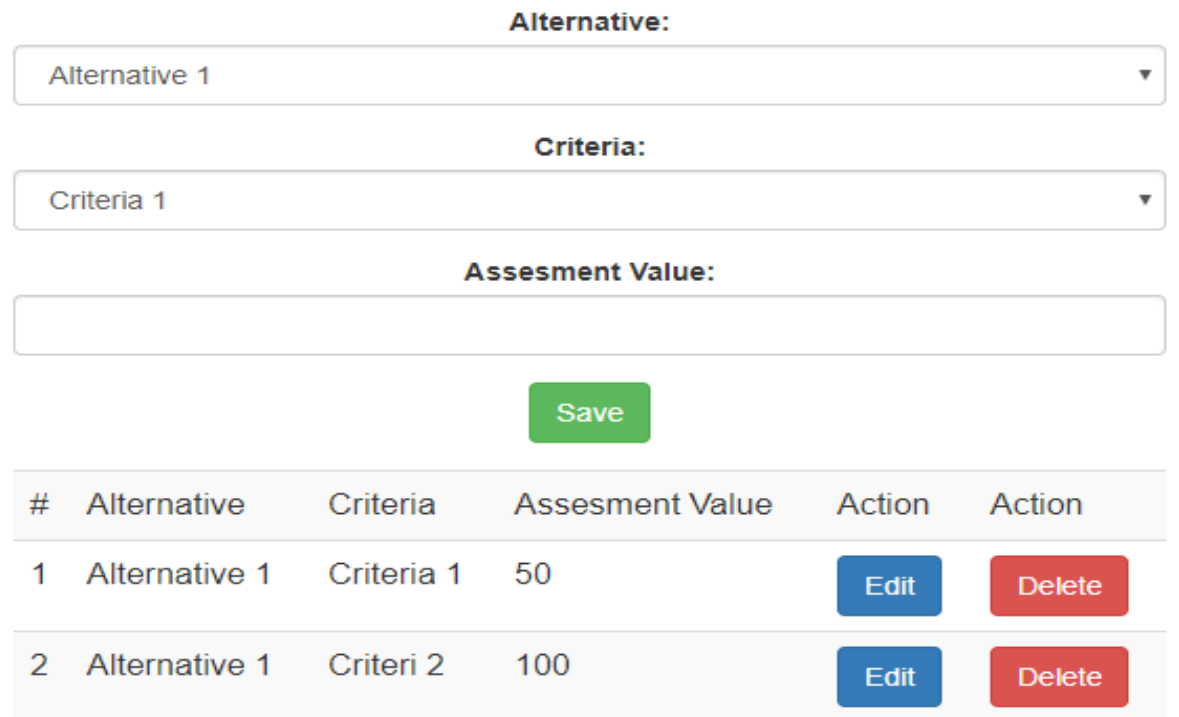

Fig. 4. Evalution form 
Fig. 5 presented the fragment of the Administrator Module, which generates a matrix of decision based on the assessments already made before and make alternatives ranking.

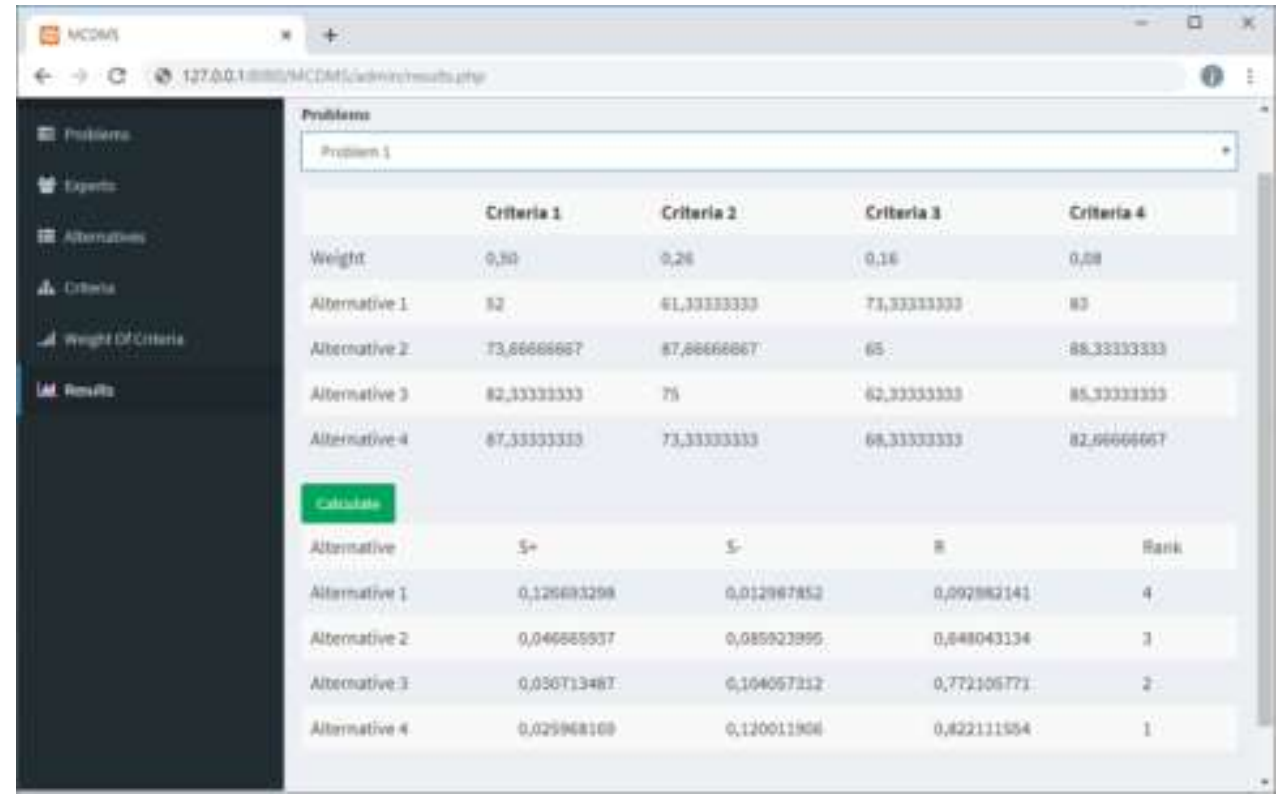

Fig. 5. Results

\section{Conclusion}

The paper describes the expert decision-making algorithm based on the AHP and TOSPIS methods for making the multi-criteria decisions through which we can solve the decision-making problems based on the experts' assessments. To demonstrate the results of running the algorithm, a simple web application has been developed to provide a solution to the problem. As a result of the development and improvement of the developed web application, we will get the expert decision support system, through which we will be able to solve different types of the expert decision problem, such as: credit risk management, project assessment and so on.

\section{References}

1. S t e v e n, L. A. Decision Support Systems: Current Practice and Continuing Challenges Reading. - Massachusetts: Addison-Wesley Publishing, Co., 1980. 316 p.

2. S a b a e vi, D., J. E r k o y u n c u, R. R o y. A Review of Multi-Criteria Decision Making Methods for Enhanced Maintenance Delivery. - Procedia CIRP, Vol. 37, 2015, pp. 30-35.

3. C. Kahraman, Ed. Fuzzy Multi-Criteria Decision Making: Theory and Applications with Recent, Developments. Springer Science \& Business Media, 2008.

4. E h r g o t t, M., J. Fi g u e i r a, S. G r e c o. Trends in Multiple Criteria Decision Analysis. Vol. 6. New York, Springer, 2010, pp. 10-34. 
5. K u m a r, R., K. S i n g h, S. K. J a i n. A Combined AHP and TOPSIS Approach for Prioritizing the Attributes for Successful Implementation of Agile Manufacturing. - International Journal of Productivity and Performance Management, 2020.

6. L i, J., J. Q. W a n g. Multi-Criteria Decision-Making with Probabilistic Hesitant Fuzzy Information Based on Expected Multiplicative Consistency. - Neural Computing and Applications, 2018, pp. 1-19.

7. B a she le is hvili, I., S. Ts i r a mua. Development of Method of Multifunctional Personnel Assessment Using a Topsis Method. - Journal of Technical Science and Technologies, Vol. 6, 2018, No 2, pp. 31-36.

8. B a she le i shvili, I., A. B a rd a veli dze. Development of Human Resource Assessment and Selection Model for Computer System Design. - International Journal of Computer (IJC), Vol. 30, 2018, No 1, pp. 50-58.

9. B a s he 1 e i s h vi 1 i, I., A. B a r d a v e 1 i d z e. Designing the Decision-Making Support System for the Assessment and Selection of the University's Academic Staff. - International Journal on Information Technologies \& Security, Vol. 11, 2019, No 2, pp. 51-59.

10. B a s he 1 e i s h vi 1 i, I., A. B a r d a v e 1 i d z e, S. T s i r a m u a. The Development of a Model for Decision Support System of Assessment and Selection of University Academic Staf. - Journal of Intelligent Systems: Theory and Applications, Vol. 2, 2019, No 2, pp. 18-23.

Received: 13.02.2020; Second Version: 12.04.2020; Accepted: 28.04.2020 